\title{
Perception and practice of early initiation of breastfeeding and associated factors among postnatal mothers in East Sikkim
}

\author{
Nisha Rakhi Tirkey, Barkha Devi*, Sonam Zangmu Sherpa
}

Department of OBG Nursing, Sikkim Manipal College of Nursing, Sikkim Manipal University, Manipal, India

Received: 27 June 2021

Revised: 27 July 2021

Accepted: 29 July 2021

\section{*Correspondence:}

Dr. Barkha Devi,

E-mail: barkhadevi2@gmail.com

Copyright: ( ) the author(s), publisher and licensee Medip Academy. This is an open-access article distributed under the terms of the Creative Commons Attribution Non-Commercial License, which permits unrestricted non-commercial use, distribution, and reproduction in any medium, provided the original work is properly cited.

\section{ABSTRACT}

Background: Breastfeeding is the most desirable method for achieving a normal growth and development of the child. Breastfeeding practice is multifactorial, and number of variables influence mothers' decisions and ability to breastfeed. This study aimed to assess the perception and practice regarding early initiation of breastfeeding and factors associated with breastfeeding among hospitalized postnatal mothers in East Sikkim.

Methods: The descriptive study was carried out among 80 postnatal mothers who delivered term healthy babies either through normal vaginal delivery $(n=34)$ or lower segment caesarean section $(n=38)$, selected through purposive sampling technique and were interviewed within six hours of postpartum. Data were collected over a period of one month through an interview schedule to get information on feeding practice, perception and the factors responsible for delayed breastfeeding. Data analysis was done using Statistical package for social sciences (SPSS) version 16. Chi square test was used to examine the factors associated with perception and practice of early initiation of breastfeeding (within one hour of birth).

Results: The result shows that early initiation of breast feeding within one hour of birth was done by $36 \%$ of mothers after the delivery and few adopted prelacteal feeding (19\%) where as $86 \%$ had positive perception towards it. The factors that mostly influenced early initiation of breastfeeding were planned pregnancy (100\%) and support from family members during pregnancy and delivery (100\%). There was a statistically significant association between mother's educational status and information regarding early initiation of breastfeeding and influencing factors like breastfeeding education during antenatal period and guidance from the health professional $(\mathrm{p}<0.05)$.

Conclusions: Early initiation of breastfeeding within one hour was found extremely low which is an alarming. The findings also suggest the need of breastfeeding promotion programs among the mothers who are less educated. Such breastfeeding promotion programmes could be implemented through network of community-based workers.

Keywords: Breastfeeding, Breast milk, Early initiation of breastfeeding, Postnatal mother, Colostrum

\section{INTRODUCTION}

Breastfeeding is an ancient practice of most women in the country. Breast feeding is the best feed for babies and it is the unique source of nutrition that plays an important role in the growth, development and survival of infants. ${ }^{1,2}$ The first hour after birth is the most crucial time period for a baby. This is a very sensitive period as the colostrum is delivered through breastfeeding which provides a protective effect to the babies which may be related to the mechanisms that include intestinal colonization by some specific type of bacteria found exclusively in maternal milk, and the ability of breast milk to produce bioactive immune factors suitable for the newborn. ${ }^{2-4}$

National Family Health Survey 2015-16 (NHFS-4) indicates that, in India only $41.6 \%$ of children are breastfed 
within the first hour of birth. This means a lost opportunity to give the child colostrum (the first secretion after birth, rich in antibodies). ${ }^{5}$ Timely initiation of breastfeeding has been reported to reduce neonatal mortality by $19.1 \%$. The WHO and UNICEF recommend that breastfeeding must be initiated within the first hour after the birth. Boccolini et al, conducted a correlational study on Breastfeeding during the first hour of life and rates of neonatal mortality. Findings showed that breastfeeding within the first hour of life was negatively correlated with neonatal mortality and this correlation was stronger among countries with more than 29 neonatal deaths per 1000 newborns. ${ }^{6}$

Srikanth et al, conducted a study on beliefs and practices of newborn feeding in various tribal communities in India. The result shows that the pre-lacteal feeds such as sugar or salt solution plain, water, diluted cow's milk honey, and milk mixed with jaggery had been fed to the newborns babies. It was also observed that majority beliefs that prelacteal feeds help to clean the tongue stimulate suckling and resist hunger. The most common beliefs which were observed among tribes regarding delayed initiation of breastfeeding was it is not ready to be fed for 3 days and harmful for the babies. The reasons for discarding colostrum were that it was impure, causes indigestion or diarrhea. ${ }^{7}$ In different geographic locations of India these types of harmful practices were observed to be prevalent among most of the tribes. The study concluded that there is a need to explore the area specific tribal cultural feeding beliefs and practices. ${ }^{8}$

There is a plenty of anecdotal reports are available which suggest that the incidence of breastfeeding is declining in almost all parts of the world probably because of increasing modernization, early initiation of complimentary feeds and introduction of artificial feeds. This could be attributed to increasing educational levels, with mothers being more employed. Growing evidence points to the impact of early initiation of breastfeeding on neonatal mortality. A 2006 study in rural Ghana showed that early initiation within the 1 st hour of birth could prevent $22 \%$ of neonatal deaths and initiation within the 1 st day could prevent $16 \%$ of deaths, while a study in Nepal found that approximately $19.1 \%$ and $7.7 \%$ of all neonatal deaths could be avoided with universal initiation of breastfeeding within the 1st hour and 1st day of life, respectively. ${ }^{9,10}$ A study in India showed that neonatal and post neonatal deaths were around five to six times lower in those infants who were fed colostrum than those who were not. ${ }^{19}$ However, in the world's most affluent societies, breastfeeding appears to be a disappearing art and the feeding bottle has replaced the breast. ${ }^{11}$

Sowmini et al, conducted a cross-sectional study of 188 mothers to study their perceptions and practices regarding breastfeeding in Mangalore, India and found that breastfeeding is influenced by race, socioeconomic factors, and cultural and educational background of parents and concluded that key to successful breastfeeding is strict and continuous vigilance over child feeding practice for timely interventions, to ensure optimal growth and development in the infant. ${ }^{12}$

According to the Lancet series breastfeeding could save 820,000 lives annually, these means that it prevents $13 \%$ under five deaths of all children. The other advantage of breastfeeding is that it can reduce about half of all diarrhea episodes and respiratory infections in lower and middleincome countries. For India it could reduce 156,000 child deaths each year, reduce a minimum of $3,436,560$ respiratory infections and 3,900,000 episodes of diarrhea, particularly in young children. ${ }^{13,14}$ The health benefits is not only restricted to the babies but it is also extended to the mother. It helps in the reductions for risk of breast and ovarian cancer. Globally each year, if the trend of breastfeeding is increased, it could prevent 20,000 deaths alone from breast cancer which is based on the findings from all the existing research and according to new calculation of estimates created for these findings. For India considering that $7 \%$ protection provided by breastfeeding could prevent 4915 deaths annually out of 70,000 deaths that occur due to breast cancer. This would help achieve the Sustainable Development Goal (SDGs) targets. ${ }^{14,15}$ The objectives of the study were to assess the perception on early initiation of breastfeeding, assess the practice of early initiation of breastfeeding, identify the associated factors of early initiation of breastfeeding among postnatal mothers, find out the association between perception and practice on early initiation of breastfeeding with associated factors and selected demographic variables.

\section{METHODS}

Non-experimental survey approach with Descriptive research design was used with the objective to assess the perception, practice and associated factors of early initiation of breastfeeding among postnatal mothers and finds association between perception and practice with associated factors and selected demographic variables. The study was conducted among 80 postnatal mothers admitted in the Central Referral Hospital (C.R.H.) and Government hospital, Gangtok, East Sikkim in 2019. The duration of the study was one month. Purposive sampling technique was used to select Postnatal mothers who delivered through normal vaginal delivery and cesarean section under spinal anesthesia, within the age group of 18 years or above and were available during data collection period.Postnatal mothers having contraindicated for breastfeed their babies like mother's having chronic disease such as active TB, AIDS, addicted to alcohol or heavy doses of some drugs etc as well as babies having condition like galactosemia, congenital lactose intolerance, congenital malformation like cleft palate and cleft lip were excluded from the study.

The data was collected through structured interview schedule were face to face interview was conducted with postnatal mothers within 6 hour of postpartum period. Three predesigned structured tool was developed to assess 
the perception, practice of early initiation of breastfeeding and associated factors of early initiation of breastfeeding among postnatal mothers for which validity and reliability was established. The permission was taken from the Hospital authority. Tool I had two sections, Section I had of socio-demographic variables to collect the background information in relation to in terms of Age, marital status, occupation, educational status, religion, type of family, family monthly income, information on early initiation of breastfeeding, current pregnancy and current mode of delivery. Section II had practice profile to measure the practice of early initiation of breastfeeding in terms of breastfeeding the baby, time of first feed, frequency of breastfeeding within first 24 hours, duration of initial breastfeed at each breast, response shown by baby, colostrum given, practice of prelacteal feeding and feeding pattern among the postnatal mothers.

Tool II was 5-point Likert scale to measure the perception on early initiation of breastfeeding. It comprises of items under the following domains - advantages of early initiation of breastfeeding for a mother and a baby, sociocultural and socio-economic factors and personal belief regarding early initiation of breastfeeding. It included both positive and negative statements. Score from $\geq 50 \%$ (61120) was considered as positive perception while score from $\leq 49 \%$ (24- 60) as negative perception. Tool III had questionnaire on associated factors with early initiation of breastfeeding. It is further divided into influencing and hindering factors under the following domains - health related factors, delivery related factors, socio-economic factors and the individual factors. The influencing factors were administered to participants practicing breastfeeding and hindering factors were given to participants who did not practice breastfeeding. Reliability of the tool was tested by Intra-rater method for socio-demographic profile $(\mathrm{r}=100 \%)$, practice $(\mathrm{r}=93 \%)$, and associated factors of early initiation of breastfeeding $(\mathrm{r}=100 \%)$, whereas Cronbach's Alpha test was used for perception on early initiation of breastfeeding ( $\mathrm{r}=0.9)$. Ethical permission was sought and informed written consent was obtained prior to the interview.

Data analysis was done using Statistical package for social sciences (SPSS) version 16. Chi square test was used to examine the factors associated with perception and practice of early initiation of breastfeeding (within one hour of birth) when testing the hypothesis. Statistical difference was considered significant as the p-value was less than 0.05 at $95 \%$ confidence level.

\section{RESULTS}

\section{Findings related to demographic characteristics of the postnatal mothers}

Most of the postnatal mothers $(55 \%)$ belonged to the age group of 21-30 years. All were married and living with their spouse. $70 \%$ of postnatal mothers were unemployed. Most of the postnatal mothers $(34 \%)$ were educated up to secondary education. Maximum numbers $(53 \%)$ of postnatal mothers were Hindu by religion. Most of the postnatal mothers $(55 \%)$ belonged to joint family.32\% of them had family monthly income within the range of Rs. 10001-15000. Majority (60\%) of the postnatal mothers had no information regarding early initiation of breastfeeding (EIBF). Majority (53\%) of postnatal mothers had their first pregnancy. $55 \%$ of postnatal mothers underwent caesarean section.

Table 1: Area wise score of perception on early initiation of breastfeeding among postnatal mothers $(\mathrm{n}=80)$.

\begin{tabular}{|lllll|l|}
\hline S. no. & Area & Mean & Mean \% & SD & Median \\
\hline $\mathbf{1}$ & Meaning & 3.53 & 70.5 & 1.25 & 4 \\
\hline $\mathbf{2}$ & Advantages of early initiation of breastfeeding for mother & 3.51 & 70.17 & 0.96 & 3.5 \\
\hline $\mathbf{3}$ & Advantage of early initiation of breastfeeding for baby & 3.66 & 73.25 & 0.96 & 4 \\
\hline $\mathbf{4}$ & Socio-cultural and socio- economic factors & 4.24 & 84.75 & 0.71 & 4 \\
\hline $\mathbf{5}$ & Personal belief regarding early initiation of breastfeeding & 3.56 & 71.13 & 1.04 & 4 \\
\hline
\end{tabular}

Table 2: Difference in level wise perception score on early initiation of breastfeeding among postnatal mothers $(\mathbf{n}=\mathbf{8 0})$.

\begin{tabular}{|c|c|c|c|c|c|}
\hline \multirow{3}{*}{ Sample } & \multicolumn{4}{|c|}{ Level of perception } & \multirow{3}{*}{ t-test } \\
\hline & \multicolumn{2}{|l|}{ Positive (69) } & \multicolumn{2}{|l|}{ Negative (11) } & \\
\hline & Mean \pm SD & Mean \% & Mean \pm SD & Mean \% & \\
\hline Postnatal mothers & $92.38 \pm 11.56$ & 76.98 & $58.73 \pm 1.27$ & 48.94 & $\begin{array}{l}23.319 * \\
(p<0.05,0.001)\end{array}$ \\
\hline
\end{tabular}

$\mathrm{df}(78)=2.00(\mathrm{p}<0.05), \mathrm{df}(78)=3.46(\mathrm{p}<0.001)$ 
Table 3: Assessment of practice related to early initiation of breastfeeding among postnatal mothers $(\mathbf{n}=\mathbf{8 0})$.

\begin{tabular}{|c|c|c|c|}
\hline S. no. & Breastfeeding practice & f & $\%$ \\
\hline \multirow[t]{4}{*}{1.} & \multicolumn{3}{|c|}{ Are you breastfeeding your baby } \\
\hline & Yes & 72 & 90 \\
\hline & No & 8 & 10 \\
\hline & If Yes $(n=72)$ & & \\
\hline \multirow[t]{3}{*}{ 1.1.1 } & \multicolumn{3}{|c|}{$\begin{array}{l}\text { Time of initiation of breastfeeding after } \\
\text { delivery }\end{array}$} \\
\hline & Within one hour & 26 & 36 \\
\hline & After one hour & 46 & 64 \\
\hline \multirow[t]{3}{*}{ 1.1.2 } & Colostrum given & & \\
\hline & Yes & 72 & 100 \\
\hline & No & 0 & 0 \\
\hline \multirow[t]{4}{*}{ 1.1.3. } & \multicolumn{3}{|c|}{$\begin{array}{l}\text { Frequency of breastfeed the baby in the } \\
\text { first } 24 \text { hours }\end{array}$} \\
\hline & $\begin{array}{l}\text { As suggested (at least every } 2 \\
\text { hours) }\end{array}$ & 12 & 17 \\
\hline & On demand & 34 & 47 \\
\hline & Randomly & 2 & 36 \\
\hline \multirow[t]{4}{*}{ 1.1.4. } & \multicolumn{3}{|l|}{ Duration of initial breastfeeding } \\
\hline & Less than 5 minutes & 20 & 28 \\
\hline & 5-10 minutes & 38 & 53 \\
\hline & More than 10 minutes & 14 & 19 \\
\hline \multirow[t]{4}{*}{ 1.1.5. } & \multicolumn{3}{|c|}{$\begin{array}{l}\text { Response shown by the baby during } \\
\text { breastfeeding }\end{array}$} \\
\hline & $\begin{array}{l}\text { Baby can easily attach to the } \\
\text { breast and suckle comfortably } \\
\text { until satisfied }\end{array}$ & 34 & 47 \\
\hline & $\begin{array}{l}\text { Baby suckles the breast and } \\
\text { release in frequent interval }\end{array}$ & 25 & 35 \\
\hline & $\begin{array}{l}\text { Baby cries during } \\
\text { breastfeeding }\end{array}$ & 13 & 18 \\
\hline 1.1.6. & \multicolumn{3}{|l|}{ Pre-lacteal feeds given } \\
\hline & Yes & 14 & 19 \\
\hline & No & 58 & 81 \\
\hline & \multicolumn{3}{|c|}{ If yes, type of pre-lacteal $(n=14)$} \\
\hline & Plain water & 4 & 29 \\
\hline & Formula milk & 8 & 57 \\
\hline & Others & 2 & 14 \\
\hline \multirow[t]{3}{*}{ 1.1.7. } & \multicolumn{3}{|l|}{ Pattern of feeding the baby } \\
\hline & Exclusive breastfeeding & 45 & 62 \\
\hline & Partial & 27 & 38 \\
\hline
\end{tabular}

Findings related to perception on early initiation of breastfeeding among postnatal mothers

The present study showed that the majority $(86 \%)$ of the postnatal mothers had a positive perception on early initiation of breastfeeding. (Figure 1)

The data further revels (Table 1) the area wise score of perception on early initiation of breastfeeding where, the mean percentage of meaning of early initiation of breastfeeding was 70.5 advantages of early initiation of breastfeeding for mother was 70.17, advantages of early initiation of breastfeeding for baby was 73.25 , sociocultural and socio- economic factors was 84.75 , personal belief regarding early initiation of breastfeeding was 71.13 .

A significant difference was noted in terms of level wise perception score on early initiation of breastfeeding with positive perception shows the mean score of 92.38 with SD 11.56, compared to the negative perception where the mean score was found to be 58.73 with SD 1.27 as evident by t-test value 23.319 with $\mathrm{df} 78=2.00$ at 0.05 level of significance as well as at 0.001 level of significance (Table 2).

Findings related to practice of early initiation of breastfeeding among postnatal mothers

Figure 2 indicates that out of 80 postnatal mothers, 72 mothers opted for breastfeeding whereas 8 did not opt for breastfeeding. The figure also shows that out of 36 postnatal mothers who delivered through normal vaginal delivery, two opted not to breastfeed whereas out of 44 postnatal mothers who delivered through caesarean section, six opted not to breastfeed. It was also revealed that $56 \%$ of the postnatal mothers who had normal vaginal delivery, initiated breastfeeding one hour after the delivery and $44 \%$ of them initiated breastfeeding within one hour after the delivery. Among the postnatal mothers who underwent cesarean delivery, $71 \%$ of them initiated breastfeeding one hour after the delivery and $29 \%$ of them initiated breastfeeding within one hour after the delivery. The data further shows that $90 \%$ of postnatal mothers were breastfeeding their baby, $64 \%$ had initiated breastfeeding after one hour and $100 \%$ of them gave colostrum to their baby. Most of them (47\%) breastfed their baby on demand and about $53 \%$ of postnatal mothers provided initial breastfeeding for approximately 5-10 minutes. $47 \%$ of the babies could easily attach to the breast and suck comfortably until satisfied. Majority $(81 \%)$ did not give any pre-lacteal feeds to their baby Most of the them (62\%) provided exclusive breastfeeding to their baby (Table 3)

\section{Findings related to associated factors in relation to early initiation of breastfeeding among postnatal mothers}

The present study showed that the majority of the factors that influence early initiation of breastfeeding were planned pregnancy $(100 \%)$, support from family members during pregnancy and delivery (100\%), received constant support from the husband $(100 \%)$, received guidance from health professional (94\%) and breastfeeding education during antenatal period $(83 \%)$ (Table 4$)$. Whereas the factors that hindered the early initiation of breastfeeding were lack of knowledge regarding the advantages of early initiation of breastfeeding $(88 \%)$, separation of the baby immediately after the delivery $(75 \%)$ and insufficient milk secretion $(75 \%)$ (Table 5). 
Table 4: Influencing factors associated with early initiation of breastfeeding among postnatal mothers $(\mathrm{N}=80, \mathrm{n}=\mathbf{7 2})$.

\begin{tabular}{|c|c|c|c|c|c|}
\hline \multirow{2}{*}{ S. no. } & \multirow{2}{*}{ Influencing factors* } & \multicolumn{2}{|l|}{ Yes } & \multicolumn{2}{|l|}{ No } \\
\hline & & Frequency & $\%$ & Frequency & $\%$ \\
\hline 1 & Planned pregnancy & 72 & 100 & 0 & 100 \\
\hline 2 & Breastfeeding education during antenatal period. & 60 & 83 & 12 & 17 \\
\hline 3 & $\begin{array}{l}\text { Delivered through vaginal delivery without any } \\
\text { complication }\end{array}$ & 35 & 49 & 37 & 51 \\
\hline 4 & $\begin{array}{l}\text { Support from family members during pregnancy and } \\
\text { after delivery }\end{array}$ & 72 & 100 & 0 & 0 \\
\hline 5 & Received constant support from the husband. & 72 & 100 & 0 & 0 \\
\hline 6 & $\begin{array}{l}\text { The health care providers and birth attendant } \\
\text { encouraged to initiate breastfeed immediately after } \\
\text { delivery }\end{array}$ & 26 & 36 & 46 & 64 \\
\hline 7 & Peer support during and immediately after childbirth & 48 & 67 & 24 & 33 \\
\hline 8 & $\begin{array}{l}\text { Information regarding importance of early initiation of } \\
\text { breastfeeding on maternal and child's health. }\end{array}$ & 25 & 35 & 47 & 65 \\
\hline 9 & Received guidance from health professional. & 66 & 92 & 6 & 8 \\
\hline
\end{tabular}

*= Each participant has more than one factor

Table 5: Hindering factors associated with early initiation of breastfeeding among postnatal mothers $(\mathrm{N}=80, \mathrm{n}=\mathbf{8})$.

\begin{tabular}{|c|c|c|c|c|c|}
\hline & \multirow{2}{*}{ Hindering factors* } & \multicolumn{2}{|l|}{ Yes } & \multicolumn{2}{|l|}{ No } \\
\hline & & Frequency & $\%$ & Frequency & $\%$ \\
\hline 10. & Unwanted pregnancy. & 0 & 0 & 8 & 100 \\
\hline 11. & Baby was separated immediately after the delivery & 6 & 75 & 2 & 25 \\
\hline 12. & Felt fatigue after the delivery. & 5 & 63 & 3 & 37 \\
\hline 13. & $\begin{array}{l}\text { Not received any breastfeeding education during } \\
\text { antenatal period. }\end{array}$ & 4 & 50 & 4 & 50 \\
\hline 14. & Family restrictions. & 0 & 0 & 8 & 100 \\
\hline 15. & Flat or Inverted or retracted nipple. & 5 & 63 & 3 & 37 \\
\hline 16. & Having pain after the delivery. & 5 & 63 & 3 & 37 \\
\hline 17. & $\begin{array}{l}\text { Not get support from family members during pregnancy } \\
\text { and immediately after the delivery. }\end{array}$ & 3 & 37 & 5 & 63 \\
\hline 18. & Insufficient milk secretion. & 6 & 75 & 2 & 25 \\
\hline 19. & $\begin{array}{l}\text { Lack of knowledge regarding the advantages of early } \\
\text { initiation of breastfeeding. }\end{array}$ & 7 & 88 & 1 & 12 \\
\hline 20. & Felt breastfeeding will reduce the immunity. & 0 & 0 & 8 & 100 \\
\hline
\end{tabular}

*= Each participant has more than one factor

Table 6: Association between the perception and practice of early initiation of breastfeeding $(\mathrm{n}=\mathbf{8 0})$.

\begin{tabular}{|c|c|c|c|c|c|c|}
\hline \multirow{2}{*}{ S. no. } & \multirow{2}{*}{ Practice } & \multicolumn{2}{|c|}{ Perception } & \multirow{2}{*}{ df } & \multirow{2}{*}{$\begin{array}{l}\chi^{2} \\
\text { value }\end{array}$} & \multirow{2}{*}{$P$ value } \\
\hline & & Positive & Negative & & & \\
\hline \multirow[t]{4}{*}{1.} & \multicolumn{6}{|l|}{ Are you breastfeeding your baby } \\
\hline & Yes & 66 & 6 & 1 & 17.813 & $0.001 *$ \\
\hline & No & 3 & 5 & & & \\
\hline & \multicolumn{6}{|l|}{ If Yes $(n=72)$} \\
\hline \multirow[t]{3}{*}{ 1.1.1 } & \multicolumn{6}{|c|}{ Time of initiation of breastfeeding after delivery } \\
\hline & Within one hour & 25 & 1 & 1 & 1.07 & 0.30 \\
\hline & After one hour & 41 & 5 & & & \\
\hline \multirow[t]{4}{*}{ 1.1.2. } & \multicolumn{6}{|c|}{ Frequency of breastfeed the baby in the first 24 hours } \\
\hline & As suggested (atleast every 2 hours) & 11 & 1 & 2 & 0.617 & 0.735 \\
\hline & On demand & 32 & 2 & & & \\
\hline & randomly & 23 & 3 & & & \\
\hline 1.1.3 & Duration of initial breastfeeding at & & & & & \\
\hline
\end{tabular}




\begin{tabular}{|c|c|c|c|c|c|c|}
\hline \multirow{2}{*}{ S. no. } & \multirow{2}{*}{ Practice } & \multicolumn{2}{|c|}{ Perception } & \multirow{2}{*}{ df } & \multirow{2}{*}{$\chi^{2}$} & \multirow{2}{*}{$P$ value } \\
\hline & & Positive & Negative & & & \\
\hline & Less than 5 minutes & 18 & 2 & 2 & 0.108 & 0.947 \\
\hline & 5-10 minutes & 35 & 3 & & & \\
\hline & More than 10 minutes & 13 & 1 & & & \\
\hline \multirow[t]{4}{*}{ 1.1.4 } & Response shown by the baby during breastfee & ling & & & & \\
\hline & $\begin{array}{l}\text { Baby can easily attach to the breast and suckle } \\
\text { comfortably until satisfied }\end{array}$ & 33 & 1 & 2 & 2.580 & 0.275 \\
\hline & $\begin{array}{l}\text { Baby suckles the breast and release in frequent } \\
\text { interval }\end{array}$ & 22 & 3 & & & \\
\hline & Baby cries during breastfeeding & 11 & 2 & & & \\
\hline \multirow[t]{3}{*}{ 1.1.5. } & Pre-lacteal feeds given & & & & & \\
\hline & Yes & 10 & 4 & 1 & 9.318 & $0.002 *$ \\
\hline & No & 56 & 2 & & & \\
\hline \multirow[t]{3}{*}{ 1.1.6. } & Pattern of feeding the baby & & & & & \\
\hline & Exclusive breastfeeding & 44 & 1 & 1 & 5.867 & $0.015^{*}$ \\
\hline & Partial & 22 & 5 & & & \\
\hline
\end{tabular}

$*$ Significant $(\mathrm{P}<0.05)$

Table 7: Association between perceptions on early initiation of breastfeeding with influencing factors $(\mathrm{N}=\mathbf{8 0}, \mathrm{n}=\mathbf{7 2})$.

\begin{tabular}{|c|c|c|c|c|c|c|}
\hline \multirow{2}{*}{ S. no. } & \multirow{2}{*}{ Influencing factors } & \multicolumn{2}{|c|}{ Perception } & \multirow{2}{*}{ df } & \multirow{2}{*}{$\chi^{2}$ value } & \multirow{2}{*}{ P value } \\
\hline & & Positive & Negative & & & \\
\hline \multirow[t]{3}{*}{1.} & \multicolumn{6}{|c|}{ Breastfeeding education during antenatal period. } \\
\hline & Yes & 59 & 1 & 1 & 20.94 & $0.001 *$ \\
\hline & No & 7 & 5 & & & \\
\hline \multirow[t]{3}{*}{2.} & \multicolumn{6}{|c|}{ Delivered through vaginal delivery without any complication. } \\
\hline & Yes & 32 & 3 & 1 & 0.005 & 0.943 \\
\hline & No & 34 & 3 & & & \\
\hline \multirow[t]{3}{*}{3.} & \multicolumn{6}{|c|}{$\begin{array}{l}\text { The health care providers and birth attendant encouraged to initiate breastfeed immediately after } \\
\text { delivery. }\end{array}$} \\
\hline & Yes & 25 & 1 & 1 & - & \\
\hline & No & 41 & 5 & & 1.073 & 0.30 \\
\hline \multirow[t]{3}{*}{4} & \multicolumn{6}{|c|}{ Peer support during and immediately after childbirth. } \\
\hline & Yes & 44 & 4 & 1 & 0.001 & 1.00 \\
\hline & No & 22 & 2 & & & \\
\hline \multirow[t]{3}{*}{5.} & \multicolumn{6}{|c|}{ Information regarding importance of early initiation of breastfeeding on maternal and child's health } \\
\hline & Yes & 24 & 1 & 1 & 0.941 & 0.332 \\
\hline & No & 42 & 5 & & & \\
\hline 6. & \multicolumn{6}{|c|}{ Received guidance from health professional. } \\
\hline & Yes & 64 & 2 & 1 & 29.157 & $0.001 *$ \\
\hline & No & 2 & 4 & & & \\
\hline
\end{tabular}

$*$ Significant $(\mathrm{P}<0.05)$

Table 8: Association between perceptions on early initiation of breastfeeding with hindering factors $(\mathrm{N}=\mathbf{8 0}, \mathrm{n}=\mathbf{8})$.

\begin{tabular}{|lllllll|}
\hline S. no. & Hindering factors & Perception & Negative & dif & $\begin{array}{c}\chi_{c}^{2} \\
\text { value }\end{array}$ & Remark \\
\hline 1. & Unwanted pregnancy & & & & \\
\hline & Yes & 0 & 0 & - & - & Not applicable \\
\hline & No & 5 & & & \\
\hline 2. & Baby was separated immediately after the delivery & & & & \\
\hline & Yes & 2 & 4 & 1 & 1.6 & Not significant \\
\hline & No & 1 & 1 & & & \\
\hline 3. & Felt fatigue after the delivery & & & & & \\
\hline & Yes & 2 & 3 & 1 & 0.032 & Not significant \\
\hline
\end{tabular}




\begin{tabular}{|c|c|c|c|c|c|c|}
\hline \multirow{2}{*}{ S. no. } & \multirow{2}{*}{ Hindering factors } & \multicolumn{2}{|c|}{ Perception } & \multirow{2}{*}{ df } & \multirow{2}{*}{$\begin{array}{l}\chi_{c}^{2} \\
\text { value }\end{array}$} & \multirow{2}{*}{ Remark } \\
\hline & & Positive & Negative & & & \\
\hline & No & 1 & 2 & & & \\
\hline \multirow[t]{3}{*}{4.} & Not received any $b$ & on during & natal perio & & & \\
\hline & Yes & 1 & 3 & 1 & 2.133 & Not significant \\
\hline & No & 2 & 2 & & & \\
\hline \multirow[t]{3}{*}{5.} & Family restriction & & & & & \\
\hline & Yes & 0 & 0 & - & - & Not applicable \\
\hline & No & 3 & 5 & & & \\
\hline \multirow[t]{3}{*}{6.} & Flat or Inverted o & & & & & \\
\hline & Yes & 2 & 3 & 1 & 0.32 & Not significant \\
\hline & No & 1 & 2 & & & \\
\hline \multirow[t]{3}{*}{7.} & Having pain after & & & & & \\
\hline & Yes & 2 & 3 & 1 & 0.032 & Not significant \\
\hline & No & 1 & 2 & & & \\
\hline \multirow[t]{3}{*}{8.} & Not get support fro & during pr & cy and im & ately & er the $d$ & \\
\hline & Yes & 2 & 1 & 1 & 0.32 & Not significant \\
\hline & No & 1 & 4 & & & \\
\hline \multirow[t]{3}{*}{9.} & Insufficient breast & & & & & \\
\hline & Yes & 3 & 3 & 1 & 0.177 & Not significant \\
\hline & No & 0 & 2 & & & \\
\hline \multirow[t]{3}{*}{10.} & Lack of knowledge & tages of & initiation 0 & astf & & \\
\hline & Yes & 2 & 5 & 1 & 6.171 & $\begin{array}{l}\text { Significant } \\
(\mathrm{p}<0.05)\end{array}$ \\
\hline & No & 1 & 0 & & & \\
\hline \multirow[t]{3}{*}{11.} & Felt breastfeeding & Inity & & & & \\
\hline & Yes & 0 & 0 & - & - & Not applicable \\
\hline & No & 3 & 5 & & & \\
\hline
\end{tabular}

Table 9: Association between perception of early initiation of breastfeeding with demographic variables $(\mathrm{n}=\mathbf{8 0})$.

\begin{tabular}{|c|c|c|c|c|c|c|}
\hline \multirow{2}{*}{ S. no. } & \multirow{2}{*}{ Demographic variables } & \multicolumn{2}{|c|}{ Perception } & \multirow{2}{*}{ df } & \multirow{2}{*}{$x^{2}$ value } & \multirow{2}{*}{$P$ value } \\
\hline & & Positive & Negative & & & \\
\hline \multirow[t]{4}{*}{1.} & Age in years & & & & & \\
\hline & $\leq 20$ & 10 & 3 & 2 & 2.016 & 0.365 \\
\hline & $21-30$ & 40 & 4 & & & \\
\hline & $\geq 31$ & 19 & 4 & & & \\
\hline \multirow[t]{3}{*}{2.} & Occupation & & & & & \\
\hline & Employed & 22 & 2 & 1 & 0.848 & 0.357 \\
\hline & Unemployed & 47 & 9 & & & \\
\hline \multirow[t]{5}{*}{3.} & Educational status & & & & & \\
\hline & No formal education & 7 & 5 & 3 & 11.972 & $0.007 *$ \\
\hline & Primary education & 17 & 4 & & & \\
\hline & Secondary education & 26 & 1 & & & \\
\hline & Graduation and above & 19 & 1 & & & \\
\hline \multirow[t]{5}{*}{4.} & Religion & & & & & \\
\hline & Hindu & 38 & 4 & 3 & 2.545 & 0.467 \\
\hline & Christian & 9 & 1 & & & \\
\hline & Buddhist & 17 & 4 & & & \\
\hline & Others & 5 & 2 & & & \\
\hline \multirow[t]{4}{*}{5.} & Type of family & & & & & \\
\hline & Nuclear family & 20 & 2 & 2 & 1.099 & 0.577 \\
\hline & Joint family & 38 & 6 & & & \\
\hline & Extended family & 11 & 3 & & & \\
\hline
\end{tabular}




\begin{tabular}{|c|c|c|c|c|c|c|}
\hline \multirow{2}{*}{ S. no. } & \multirow{2}{*}{ Demographic variables } & \multicolumn{2}{|c|}{ Perception } & \multirow{2}{*}{ df } & \multirow{2}{*}{$\chi^{2}$ value } & \multirow{2}{*}{$P$ value } \\
\hline & & Positive & Negative & & & \\
\hline \multirow[t]{5}{*}{6.} & Family monthly income (Rs.) & & & & & \\
\hline & $\leq 5000$ & 12 & 2 & 3 & 1.898 & 0.594 \\
\hline & $5001-10000$ & 19 & 3 & & & \\
\hline & $10001-15000$ & 24 & 2 & & & \\
\hline & $\geq 15001$ & 14 & 4 & & & \\
\hline \multirow[t]{3}{*}{7.} & Information regarding EIBF & & & & & \\
\hline & Yes & 31 & 1 & 1 & 5.077 & $0.024 *$ \\
\hline & No & 38 & 10 & & & \\
\hline \multirow[t]{4}{*}{8.} & Current pregnancy & & & & & \\
\hline & First & 35 & 7 & 2 & 0.705 & 0.703 \\
\hline & Second & 23 & 3 & & & \\
\hline & Third or more & 11 & 1 & & & \\
\hline \multirow[t]{3}{*}{9.} & Current mode of delivery & & & & & \\
\hline & Normal vaginal delivery & 32 & 4 & 1 & 0.384 & 0.535 \\
\hline & Caesarean delivery & 37 & 7 & & & \\
\hline
\end{tabular}

$*$ Significant $(\mathrm{P}<0.05)$

Findings related to association between perception and practice on early initiation of breastfeeding among postnatal mothers

The data shows a significant association between the breastfeeding the baby with the perception on the early initiation of breastfeeding $(\mathrm{p}=0.001)$, pre- lacteal feeds given with the perception on the early initiation of breastfeeding $(\mathrm{p}=0.002)$ and pattern of feeding the baby with the perception on the early initiation of breastfeeding $(\mathrm{p}=0.015)$ (Table 6).

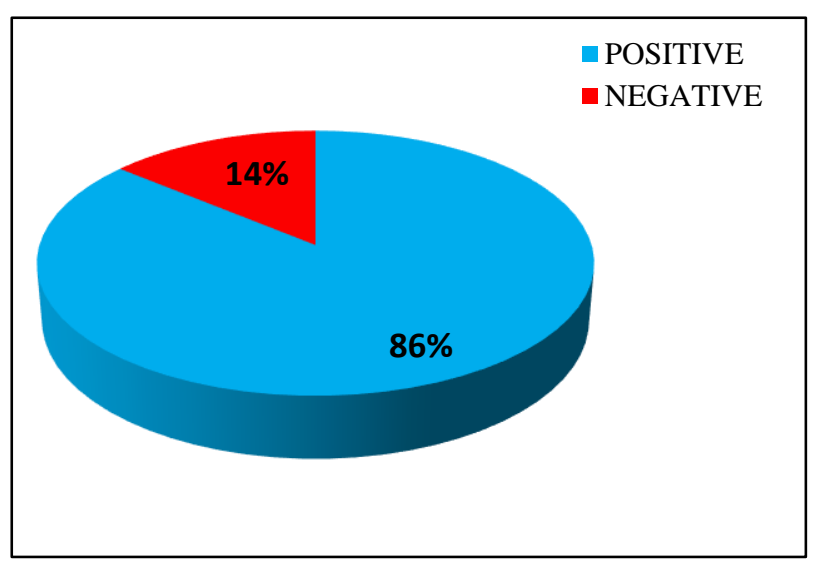

Figure 1: Postnatal mothers in terms of their perception on early initiation of breastfeeding.

Findings related to association between perception on early initiation of breastfeeding with associated factors among the postnatal mothers

The data presented in (Table 7) reveals that there was a significant association between perception on early initiation of breastfeeding with breastfeeding education during antenatal period $(\mathrm{p}<0.05)$ and guidance received from health professional during $(\mathrm{p}<0.05)$. The data further reveals significant association between the perception on the early initiation of breastfeeding with lack of knowledge regarding the advantages of early initiation of breastfeeding $(\mathrm{p}=0.05)$ (Table 8$)$.

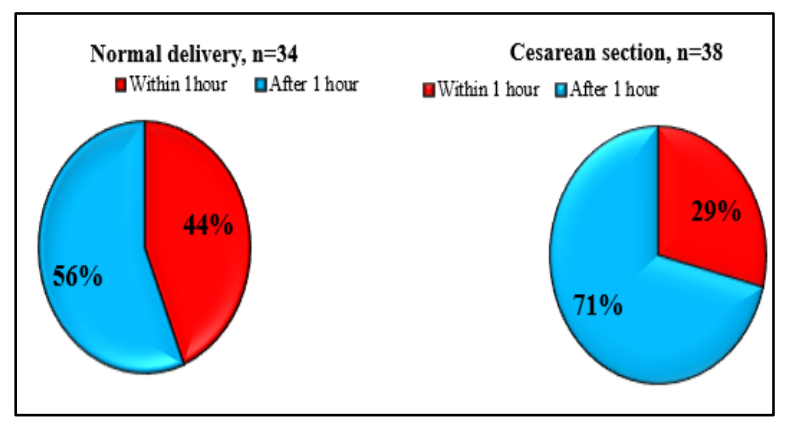

Figure 2: Distribution of postnatal mothers in terms of their mode of delivery.

Findings related to association between perception of early initiation of breastfeeding among the postnatal mothers and selected demographic variables

The present study showed that p-value corresponding to age, occupation, religion, type of family, family monthly income, current pregnancy and current mode of delivery is greater than the 0.05 level of significance, so the above stated demographic variables do not have any significant association with the perception on early initiation of breastfeeding. The data further presented reveals significant association between the perception on the early initiation of breastfeeding with educational status of the postnatal mothers $(p \leq 0.007)$ and information regarding early initiation of breastfeeding among postnatal mothers $(\mathrm{p} \leq 0.024)$ (Table 9).

\section{DISCUSSION}

Most of the postnatal mothers (55\%) belonged to the age group of 21-30 years. 100\% were married and living along 
with their spouse. Majority $(70 \%)$ of postnatal mothers were unemployed. Most of the postnatal mothers 34\% had secondary education. Maximum numbers $(53 \%)$ of postnatal mothers belonged to Hindu religion. Most of the postnatal mothers $(55 \%)$ belonged to joint family. $32 \%$ of them had family monthly income from Rs. 10001-15000. Majority $(60 \%)$ of the postnatal mothers had no information regarding early initiation of breastfeeding (EIBF). Majority (53\%) of postnatal mothers had their first pregnancy. Majority (55\%) of postnatal mothers underwent caesarean section. The present study revealed that most of the postnatal mothers had positive perception on early initiation of breastfeeding and all of them had given colostrum to their baby. The finding of the present study is in contrast with the study conducted by Rogers et al the findings of which showed that colostrum was considered as heavy, thick, dirty, toxic and harmful to children's' health and therefore a portion of colostrum was discarded. ${ }^{15}$ The result of the present study is also in contrast with the study conducted by Kamath et al where the findings revealed that there was poor perception regarding the advantages of breast milk with respect to immune effect, disease protection and nutritive value. ${ }^{16}$

In the present study $36 \%$ of the postnatal mothers initiated breastfeeding within 1 hour which is in contrast with the study conducted by Babu et al., findings showed that the early initiation of breastfeeding occurred only in $1.4 \%$ of the babies. ${ }^{17}$ The finding of the present study is also in contrast with the study conducted by Kumar et al, where it was found that $6.3 \%$ of the mothers initiated breastfeeding within one hour of birth. In the present study, the breastfeeding initiation rate was $90 \%$ out of which the early initiation of breastfeeding within one hour was found in $36 \%$ which is consistent with the study conducted by Ahmed et al where the findings showed that the breastfeeding initiation rate was $97.3 \%$ and early initiation of breastfeeding within 1 hour of birth was $43.6 \%$ among all mothers. ${ }^{18}$ The present study showed that $64 \%$ of postnatal mothers did not initiate the breastfeeding within one hour of birth which is consistent with the study conducted by Das et al where the findings revealed that $65.8 \%$ mothers did not initiate the breastfeeding within one hour of birth. ${ }^{19}$ In the present study, prelacteal feeds were given to $19 \%$ of the babies which is consistent with the study conducted by Chea et al where the findings showed that $25.5 \%$ of newborn babies were exposed to prelacteal feeding. ${ }^{20,21}$ In the present study, lack of knowledge regarding the advantages of early initiation of breastfeeding and the delay in shifting to indoor wards were found to delay the initiation of breastfeeding. This in turn increased the prelacteal feeding which is consistent with the study conducted by Bhatt et al which reported that delay in rooming-in, mother's knowledge on early initiation of breastfeeding and shifting to indoor wards led to delay in initiation of breastfeeding and the increased use of prelacteal feeds. ${ }^{22}$

The present study showed that planned pregnancy and support from family members are the major influencing factors for breastfeeding the baby which is consistent with the study conducted by Hinson et al in which it was found that influence of family, peer networks, intension and information sources were the factors which influence breastfeeding. In the present study, the main reported reason for delaying early initiation of breastfeeding beyond 1 hour of birth was the delay from the place of delivery i.e. mothers and babies were separated immediately after birth and lack of knowledge regarding the advantage of early initiation of breastfeeding which is consistent with the study conducted by Ahmed et al where the findings revealed that the main reported reason for delaying early initiation of breastfeeding beyond 1 hour of birth was the delay from the place of delivery (40.9\%) i.e. mothers and babies were separated immediately after birth and the newborn was brought back to the mother after more than 1 hour of delivery. ${ }^{19,23}$

In the present study, the statistically significant association was found between the mother's educational level and information regarding early initiation of breastfeeding with the perception on early initiation of breast feeding $(p<0.05)$ which is consistent with the study conducted by Kamath et al in which findings showed a statistically significant association between mother's educational level and perceived importance of breastfeeding. ${ }^{16}$ In the present study, the statistically significant association was found between the lack of knowledge regarding the advantages of early initiation of breastfeeding and perception on early initiation of breastfeeding which is consistent with the study conducted by Chea et al., in which findings showed that lack of knowledge was associated with prelacteal feeding. ${ }^{21}$ The major limitation of the study was the sampling technique and the study setting which was confined to only two hospitals which poses a problem for generalization of the findings.

\section{CONCLUSION}

In spite of having positive perception as well as the influencing factors associated with early initiation of breastfeeding, there was delay in early initiation of breastfeeding within 1 hour after the delivery due to lack of information on practice as well as advantage of early initiation of breastfeeding. Practices of giving colostrum, less practice of prelacteal feed and exclusive breastfeeding, and their perceptions perception towards early initiation of breastfeeding were fairly satisfactory among postnatal mothers included in this study. Inadequate information along with the inadequate adherence to the hospital policy by the health care providers who are the major source for providing information is also found to be the reason for delay in initiation of breastfeeding. In view of certain wrong practices, it would be essential to counsel mothers during antenatal period, regarding breastfeeding, stress the advantages of breast milk, and also dispel the myths and disbeliefs in them. 


\section{ACKNOWLEDGMENTS}

The investigators would like to thank Vice Principal, Sikkim Manipal College of Nursing and the participants for which without them the study would not have been a successful one.

Funding: No funding sources Conflict of interest: None declared

Ethical approval: The study was approved by the Institutional Ethics Committee

\section{REFERENCES}

1. World Health Organization. Global strategy for infant and young child feeding. 2013. http://www.who.int/nutrition/publications/gs_infant_ feeding_text_eng.pdf. Accessed on

2. Jones G, Steketee RW, Black RE, Bhutta ZA, Morris SS. How many child deaths can we prevent this year? The Lancet. 2003;362(9377):65-71.

3. Victora CG, Barros AJD. Effect of breastfeeding on infant and child mortality due to infectious diseases in less developed countries: a pooled analysis. The Lancet. 2000;355(9202):451-55.

4. Colostrum.

https://www.sciencedaily.com/terms/colostrum.htm. Accessed on

5. National Family Health Survey - 4 (2015 -16). India. Fact Sheet http://rchiips.org/NFHS/pdf/NFHS4/India.pdf. Accessed on

6. Boccolini CS, Carvalho ML, Oliveira MI, PérezEscamilla R. Breastfeeding during the first hour of life and neonatal mortality. J Pediatr (Rio J). 2013;89(2):131-6.

7. Srikanth L, Subbiah K, Srinivasan S. Beliefs and practices of newborn feeding in tribal areas of India: a decennary review. Int $\mathbf{J}$ Community Med Public Health. 2017;4:281-5.

8. Singh K, Srivastava P. The effect of colostrum on infant mortality: urban rural differentials. Health Popul Perspect. 1992;15:94-100.

9. Edmond KM, Kirkwood BR, Amenga-Etego S, Owusu-Agyei S, Hurt LS. Effect of early infant feeding practices on infection specific neonatal mortality: an investigation of the causal links with observational data from rural Ghana. Am J Clin Nutr. 2007;86:1126-31.

10. Mullany LC, Katz J, Li YM, Khatry SK, LeClerq SC, Darmstadt GL et al. Breast-feeding patterns, time to initiation, and mortality risk among newborns in southern Nepal. J Nutr. 2008;138(3):599-603.

11. Stevens EE, Patrick TE, Pickler R. A history of infant feeding. J Perinat Educ. 2009;18(2):32-9.
12. Kamath SP, Garg D, Khan MK, Jain A, Baliga SB. Perceptions and Practices regarding Breastfeeding among Postnatal Women at a District Tertiary Referral Government Hospital in Southern India. Scientifica (Cairo). 2016.

13. TIS Staffer. Breastfeeding could prevent child deaths. Lancet. 2017;8.

14. Less than $50 \%$ are breastfed in first hour of birth in India / Delhi news - Times of India/ https://timesofindia.indiatimes.com/city/delhi/Lessthan-50-are-breastfed-in-first-hour-of-birth-inIndia/articleshow/48766517.cms. Accessed on

15. Rogers NL, Abdi J, Moore D, Nd'iangui S, Smith LJ, Carlson AJ et al. Colostrum avoidance, prelacteal feeding and late breast-feeding initiation inrural Northern Ethiopia. Public Health Nutr. 2011;14(11):2029-36.

16. Kamath SP, Garg D, Khan MK, Jain A, Baliga BS. Perceptions and Practices regarding Breastfeeding among Postnatal Women at a District Tertiary Referral Government Hospital in Southern India. Scientifica (Cairo). 2016;2016:5430164.

17. Babu RA, Keepanasseril A, Kanimozhi K. Practice of early initiation of breastfeeding among postnatal mothers in a tertiary hospital in South India. Int J Adv Med Health Res. 2018;5:18-20.

18. Kumar D, Agarwal N, Swami HM. Sociodemographic correlates of breast-feeding in urban slums of Chandigarh. Indian $\mathbf{J}$ Med Sci. 2006;60(11):461-6.

19. Ahmed AE, Salih OA. Determinants of the early initiation of breastfeeding in the Kingdom of Saudi Arabia. Int Breastfeed J. 2019;14:13.

20. Das N, Chattopadhyay D, Chakraborty S, Dasgupta A. Infant and Young ChildFeeding Perceptions and Practices among Mothers in a Rural Area of West Bengal,India. Ann Med Health Sci Res. 2013;3(3):370-5.

21. Chea N, Asefa A. Prelacteal feeding and associated factors among newborns in rural Sidama, south Ethiopia: a community based cross-sectional survey. Int Breastfeed J. 2018;13:7.

22. Bhatt S, Parikh P, Kantharia N, Dahat A, Parmar R. Knowledge, attitude and practice of postnatal mothers for early initiation of breast feeding in the obstetric wards of a tertiary care hospital of Vadodara city. Natl J Community Med. 2012;3:305-9.

23. Hinson TD, Skinner AC, Lich KH, Spatz DL. Factors That Influence BreastfeedingInitiation Among African American Women. J Obstet Gynecol Neonatal Nurs. 2018;47(3):290-300.

Cite this article as: Tirkey NR, Devi B, Sherpa SZ Perception and practice of early initiation of breastfeeding and associated factors among postnatal mothers in East Sikkim. Int J Reprod Contracept Obstet Gynecol 2021;10:3494-503. 